\title{
Confluencias entre el pensamiento de Frantz Fanon y el de Paulo Freire. El surgimiento de la educación popular en el marco de la situación colonial
}

Pablo Martins*

\section{Resumen}

A partir de la centralidad de la noción de situación colonial, el texto aborda las influencia de la obra de Frantz Fanon Los condenados de la Tierra en el surgimiento de la educación popular liberadora en América Latina. Particularmente se hace referencia al impacto de la mencionada obra en los textos y la práctica educativa de Paulo Freire. Se trabaja a partir de una análisis comparativo de textos de ambos autores y se señalan aspectos relevantes en los que es posible ubicar perspectivas comunes en sus producciones. Particularmente, se señalan como elementos coincidentes los que tienen que ver con la conceptualización de la sociedad colonizada - oprimida, las formas a través de las cuales los oprimidos se constituyen en sujetos de esa sociedad y las posibilidades de transformación de las relaciones de deshumanización en relaciones de humanidad plena. El trabajo aquí presentado forma parte de una investigación más amplia aún en desarrollo.

Palabras clave: Frantz Fanon, Paulo Freire, situación colonial, educación popular.

\section{Confluence of thought of Frantz Fanon and Paulo Freire. The rise of popular education under the colonial situation}

\begin{abstract}
From the centrality of the notion of colonial situation, the text addresses the influence of the work of Frantz Fanon "The Wretched of the Earth" in the rise of popular education in Latin America. Particularly referred to the impact of that work in the texts and the educational practice of Paulo Freire. It works from a comparative analysis of texts of both authors and identifies relevant aspects in which it is possible to locate common perspectives in their productions. In particular, matching items are identified as those having to do with the conceptualization of the colonized society - oppressed society, the ways in which the oppressed are the subjects of that society and the possibilities of transforming the relations of dehumanization in relationships of full humanity. The work presented here is part of a wider investigation still in progress.
\end{abstract}

Keywords: Frantz Fanon, Paulo Freire, colonial situation, popular education.

\footnotetext{
* Profesor Doutor Adjunto del Departamento de Pedagogia, Politica y Sociedad (Facultad de Humanidades y Ciencias de la Educación - Universidad de la República, Uruguay).
} 


\section{Pablo Martins}

\section{Introducción}

El presente trabajo trata el proceso de surgimiento de la corriente de la educación popular liberadora, en el contexto de las discusiones acerca de la sociedad colonial en la América Latina de la segunda mitad del siglo XX.

Específicamente, se abordan las influencias de la obra de Frantz Fanon (puntualmente, Los condenados de la Tierra) en el pensamiento de Paulo Freire (enfatizando en La educación como práctica de la libertady Pedagogía del Oprimido).

El texto cuenta con una primera parte en la que se trabajan de las nociones de desarrollismo y situación colonial; una segunda parte en la cual se presentan algunas discusiones sobre la caracterización del pensamiento pedagógico de Paulo Freire; $y$, una tercera parte en la que se abordan algunas relaciones entre el pensamiento de Fanon y el de Freire. El trabajo cierra con unas breves conclusiones.

\section{Desarrollismo y situacion colonial}

La discusión predominante en las ciencias sociales latinoamericanas de los años 50 y 60 es acerca del desarrollo. Esta tiene que ver con cómo puede producirse el paso desde sociedades con escasos niveles de desarrollo hacia sociedades evolucionadas, de acuerdo al patrón logrado por los países centrales. Un ejemplo de la entidad de estas polémicas puede apreciarse en la disputa que se establece entre posiciones tributarias del modelo desarrollista (MEDINA ECHAVARRÍA, 1967) y la crítica marxista a esta perspectiva generada desde la teoría de la dependencia (CARDOSO; FALLETTO, 1969).

Las teorías hegemónicas sobre el desarrollo se basaron en tres principios fundamentales (AROCENA, 1995):

1. el desarrollo constituye un proceso a lo largo del cual la capacidad productiva y la estructura económica de un país se van asemejando a las de los países industriales avanzados;

2. el proceso de desarrollo es el mismo para todos los países;

3. existe una identificación entre desarrollo y crecimiento económico, entendido como formación de capital.

El desarrollo es concebido como un proceso nacional, que integra a la nación totalmente. La nación se constituye en esta perspectiva a través del proceso de modernización, el cual supone la transición de lo tradicional (incompleto) a lo moderno (completo).

A través de la teoría de la dependencia se objetan estos planteos. Esta crítica comparte, empero, la centralidad de la idea de nación. Se trata de 
Confluencias entre el pensamiento de Frantz Fanon y el de Paulo Freire. El surgimiento de la educación popular en el marco de la situación colonial

una crítica acerca del modo conservador en el que la teoría de la modernización trabaja la idea de nación (CARDOZO; FALLETO, 1969).

En el marco de estas discusiones emerge una postura crítica, con una fuerte influencia desde diversas lecturas del marxismo, que enfatiza la necesidad de ubicar estos procesos en el marco de las relaciones de poder en las que se encuentran inscriptos. Dichas relaciones van a ser presentadas a través de la noción de situación colonial. Es en esta perspectiva en la que nos va a interesar detenernos en el presente trabajo, abordando el pensamiento de uno de los articuladores de esta concepción (Frantz Fanon), a la vez que visualizando sus influencias y convergencias con el surgimiento de la corriente de la educación liberadora o popular latinoamericana, presentada en la obra de Paulo Freire.

Es importante tener en cuenta que desde la perspectiva de la situación colonial, la nación colonizada no puede serya que se encuentra alienada por su relación con la metrópoli. Se establece una relación dialéctica que se produce entre nación colonizada y nación colonizadora. El colonizado aloja en si al colonizador.

La nación colonizada para poder SER precisa DESALIENARSE, descolonizarse. Estas ideas, propias de las luchas que se desarrollaban en Asia y Africa, van a ser tomadas por autores latinoamericanos. Ellos van a plantear que el encuentro de civilizaciones y la aculturación se da en una situación colonial. El encuentro de blancos, negros e indios se da en el marco de situaciones de poder. Estas situaciones de poder pueden conceptualizarse a través de la noción de situación colonial.

La construcción de la auténtica nación se coloca en el futuro, la liberación abre el paso a la concreción del la utopía. La noción de proyecto nacional prepara la construcción de un futuro ideal, donde se ha de concretar la verdadera nación, la del pueblo que ha resistido la colonización. Por ello:

Fanon reivindica la nación en nombre de un proyecto revolucionario socialista por lo menos tanto como en nombre de las injusticias de la ocupación colonial. Así la nación no se funda tanto en el pasado como en el futuro, de allí que critique con tanta vehemencia toda tentativa de retorno a un pasado del que el folklore pretende extraer los elementos formativos de la conciencia nacional (CÓRDOBA, 1970, p. 16).

\section{Sobre la caracterización del pensamiento pedagógico de Freire}

El primer trabajo de Freire, Educação e atualidade brasileira, data de 1959. Desde allí hasta la Pedagogía de la Autonomía, de 1996, se extiende una frondosa producción bibliográfica y una abarcadora práctica educativa. Esta ha sido de relevancia en la evolución de las ideas pedagógicas latinoamericanas en el siglo XX (GADOTTI; TORRES, 2001; PUIGGRÓS, 1994). 


\section{Pablo Martins}

Existe una discusión muy extendida en el campo pedagógico acerca el tenor de los primeros trabajos de Freire. Para algunos autores sus primeros escritos son muestra de un Freire que se maneja dentro de un marco pedagógico idealista y de una visión social desarrollista; para otros, los elementos y la intencionalidad fundamentales de su obra ya se encuentran en aquellos textos pioneros.

Los primeros afirman que puede visualizarse esta primera etapa como una en la cual prima la intención de dar al pueblo una ideología de desarrollo, de educar a las masas populares para la participación crítica dentro de un modelo de desarrollo nacional. Scocuglia (1999) reconoce que en La educación como práctica de la libertad, se da una evolución en el pensamiento de Freire. De todos modos, entiende que esta evolución se da en el marco de una conceptualización del cambio social que estaba excesivamente vinculada a las transformaciones internas de los sujetos a través de su conciencia individual.

Para la postura que asume Scocuglia, y que tiene muchos simpatizantes en el campo pedagógico latinoamericano, las primeras obras de Freire no escapan a una visión ingenua de la educación. Una visión ajena a la reflexión acerca del lugar de los conflictos sociales en la constitución de lo educativo. En este sentido, constituiría una forma de ver la educación funcional a la ideología desarrollista, hegemónica en las décadas de los años 50 y 60 .

Para esta postura, la Pedagogía del Oprimido marcaría el surgimiento de un "nuevo Freire":

Não afirmamos que Marx - Engels e Gramsci, mais
Sartre, Lukács, Amilcar Cabral, entre outros, determina-
ram a ruptura com posições liberalizantes, nacionalis-
tas e desenvolvimentistas e, certamente, populistas dos
anos 50 e 60 . Como coloca o próprio autor, ele não foi
trabalhar com os grupos populares "por causa de Marx",
ao contrário, foi procurar auxílio nos marxismos (não-
ortodoxos) para compreender esses grupos. (SCOCUGLIA, 1999, p. 42)

Mas allá de la validez o no de esta postura, parece claro que la influencia de los autores mencionados en la cita provoca una profundización del pensamiento freireano. Creemos que con total justicia Frantz Fanon debiera ser colocado en dicha lista. Una justificación de esta afirmación podrá encontrarse en el desarrollo del presente trabajo.

Por otra parte, existen en el campo de la pedagogía latinoamericana una serie de autores que rechazan la tesis de la existencia de un Freire más "ingenuo" y otro más "crítico". 
Confluencias entre el pensamiento de Frantz Fanon y el de Paulo Freire. EI surgimiento de la educación popular en el marco de la situación colonial

Ellos defienden la existencia de una continuidad en su pensamiento. Argumentan que:

O debate e o combate por uma escola pública democrática e de qualidade, contra todas as formas de elitismo e de autoritarismo, e contra as modalidades perversas de exclusão, representam tema central já em sua tese para o concurso em História e Filosofia de Educação, intitulada Educação e atualidade brasileira no Recife, em 1959. (ANDREOLA, 1999, p. 78)

En este caso, se postula una continuidad en el pensamiento pedagógico de Freire. Ella está marcada por una profundización, que podría señalarse como iniciada en Pedagogía del Oprimido, de temas pedagógico - políticos ya presentes en sus primeras obras.

No debe olvidarse que el Freire que escribe la Pedagogía del Oprimido ha sido lanzada al exilio por la dictadura brasileña. Dicho exilio producirá el encuentro con intelectuales de otros lares, con los cuales las tesis pedagógicas y políticas de Freire van a ser profundamente discutidas. Así, Adriana Puiggrós (1994) plantea que el énfasis en posturas marxistas del Freire de la Pedagogía del Oprimido, se debe a la necesidad de ser aceptado por la izquierda tradicional. De todos modos: "(En la pedagogía de la liberación) los contenidos marxistas están mediatizados por el cristianismo y el nacionalismo - latinoamericanismo - tercermundismo". (PUIGGRÓS, 1994, p. 197)

Más allá de la discusión acerca de la existencia de una o dos fases en el desarrollo de su pensamiento pedagógico - político, la última cita nos abre las puertas a un elemento fundamental: la existencia de una forma particular de articular, desde un pensamiento pedagógico, aportes provenientes del marxismo, del cristianismo y de diversas posturas que desde el tercer mundo intentaban construir conocimiento acerca de la situación colonial y las formas de sus superación. Creemos que la obra de Freire constituye la base de la reflexión pedagógica de dicho pensamiento específicamente propio del tercer mundo latinoamericano.

En la construcción de este pensamiento tiene un lugar importante la lectura de la obra de Frantz Fanon, especialmente Los condenados de la Tierra, publicado en francés en 1961.

\section{Convergencias de Fanon con Freire}

Es posible encontrar una referencia a Fanon en La educación como práctica de la libertad. Es una mención ubicada en un pie de página, el de la nota número 14. No ocupa un lugar central en el conjunto de la obra, pero marca un primer nivel de lectura de Fanon. 


\section{Pablo Martins}

En la cita, que explica la emergencia de actitudes violentas por parte del "hombre radical" que reacciona frente a la violencia de la opresión, se plantea:

Pero, generalmente, cuando el oprimido se rebela legítimamente contra el opresor, en quien identifica la opresión, se le califica de violento, bárbaro, inhumano, frío. [...] Es decir, la violencia del oprimido, además de ser mera respuesta en que revela el intento de recuperar su humanidad, es, en el fondo, lo que recibió del opresor. Tal como lo señala Fanon, es con él con quien el oprimido aprende a torturar. Con una sutil diferencia en este aprendizaje: el opresor aprende al torturar al oprimido. El oprimido al ser torturado por el opresor. (FREIRE, 1987, p. 41-42)

La violencia generada desde la situación colonial y la reacción que esta genera en los colonizados es una de los temas centrales en Los condenados de la Tierra. Ello es retomado por Freire, articulado con elementos de raíz cristiana, haciendo referencia al obstáculo que para la concreción del amor supone la relación de opresión .

La referencia al ejercicio de la violencia como forma de recuperación de la humanidad y como devolución de la ejercida por el opresor, son temas que remiten a la obra de Fanon. La asunción de estos elementos por Freire se da a partir del establecimiento de una equivalencia entre los conceptos de colonizador y opresor, por una parte, y colonizado y oprimido por otro. Podemos así la existencia de un intento por pensar la situación colonialen términos de situación de opresión.

Este elemento que surge como proyecto en La educación como práctica de la libertad, se verá con mayor claridad en Pedagogía del Oprimido. En este sentido, podría discutirse la postura que habla de la existencia de dos Freire, el ingenuo y el crítico. Si tomamos como referencia la influencia de la obra de Fanon en Freire, a lo que vamos a asistir es a la profundización de una postura y no a su transformación.

De todos modos, entendemos que es en Pedagogía del Oprimido en la obra donde puede apreciarse con claridad una postura pedagógica y política centrada fuertemente en una perspectiva de crítica a una situación de opresión y en las vías para su superación.

La influencia de Fanon, sin ser la única, ocupa un lugar importante en la radicalización de esta postura. Presentaremos a continuación, sin afán de concluir el tema, tres momentos en los cuales a lo largo de Pedagogía del Oprimido, puede apreciarse la influencia de Fanon en Freire. 
Confluencias entre el pensamiento de Frantz Fanon y el de Paulo Freire. E surgimiento de la educación popular en el marco de la situación colonial

\title{
Naturaleza del vínculo colonizado - colonizador
}

La relación entre colonizador y colonizado es para Fanon una relación que se funda en el carácter violento de la situación colonial. En sus términos:

\begin{abstract}
La descolonización es el encuentro de dos fuerzas congénitamente antagónicas que extraen precisamente su originalidad de esa especie de sustanciación que segrega y alimenta la situación colonial. Su primera confrontación se ha desarrollado bajo el signo de la violencia y su cohabitación - más precisamente la explotación del colonizado por el colono - se ha realizado con un gran despliegue de bayonetas y de cañones. El colono y el colonizado se conocen desde hace tiempo. $Y$, en realidad, tiene razón el colono cuando dice conocerlos. Es el colono el que ha hecho y sigue haciendo al colonizado. (FANON, 1974, p. 31)
\end{abstract}

Esta violencia claramente presentada en la obra de Fanon, es entendida por Freire como constitutiva también de la relación opresor - oprimido. La construcción del oprimido por el opresor, que supone la negación de una identidad propia y la imposición de otra, es un tema recurrente en Freire.

Esta temática surge vinculada a la deshumanización inherente a la opresión. Freire hace referencia a la situación a través del concepto de "dualidad existencial del oprimido": los propios oprimidos alojan dentro de si al opresor. Parafraseando a Fanon, se trata de cómo el opresor ha hecho y sigue haciendo al oprimido, sin permitir que este reconozca claramente al opresor, ni pueda tampoco auto-reconocerse.

Para Freire esta dualidad existencial del oprimido se expresa en cuatro características:

1) la asunción de actitudes fatalistas. El asumir su realidad de oprimido como un dato de la realidad, inamovible y natural. Para Freire, "este fatalismo, manifestado como docilidad, es producto de una situación histórica y sociológica y no un trazo esencial de la forma de ser del pueblo". (FREIRE, 1987, p. 57)

Dentro del mundo mágico o mítico en el que se encuentra la conciencia oprimida, el fatalismo toma la forma de una aceptación de un destino existente por fuera de los sujetos o del reconocimiento de la voluntad de Dios.

Esta apreciación del papel de la religión como sustento de posturas fatalistas por parte de los oprimidos está presente en la obra de Fanon. Este reflexiona sobre las formas a través de las cuales los colonizados evitan, en 


\section{Pablo Martins}

determinados momentos y situaciones, reconocer en el colono el origen de su situación de subordinación. En relación al elemento religioso, plantea:

El colonizado logra igualmente, mediante la religión, no tomar en cuenta al colono. Por el fatalismo, se retira al opresor toda iniciativa, la causa de los males, de la miseria, del destino están en Dios. (FANON, 1974, p. 48)

Nótese la similitud de las apreciaciones que realizan los autores y el lugar que el fatalismo adquiere en la constitución de una identidad subordinada. Ambos reconocen que esta visión de los acontecimientos no surge naturalmente de los sujetos, sino que es fruto de procesos históricos y sociales.

Buscar trascender esta visión fatalista del mundo es un tema central en la obra de ambos autores. Para los dos la objetivación por parte de los oprimidos de su situación de opresión constituye un elemento central. Así, la organización y la acción de los oprimidos comienza a constituirse en camino para la superación de la opresión.

2) Freire se refiere a la explosión de la violencia de los oprimidos, que se vuelca sobre otros oprimidos

Al no poderse apreciar claramente el "orden" dentro del cual se produce la opresión, la violencia que la misma genera en los oprimidos se expresa de forma horizontal, agrediéndose "a los propios compañeros oprimidos por los motivos mas nimios". (FREIRE, 1987, p. 58)

Al introducir esta segunda característica, Freire se refiere explícitamente a Fanon en Los condenados de la Tierra. Cita: "El colonizado no deja de liberarse entre las nueve de la noche y las seis de la mañana. Esa agresividad manifestada en sus músculos va a manifestarla el colonizado primero contra los suyos" (FANON, 1965 apud FREIRE, 1987, p. 58). Esta es la única parte en el desarrollo de toda Pedagogía del Oprimido en la que Fanon es directamente citado por Freire.

\section{por parte del oprimido}

3) La existencia de un sentimiento de atracción hacia el opresor

En uno de los extremos de la dualidad, "en su enajenación quieren, a toda costa, parecerse al opresor, imitarlo, seguirlo. Esto se verifica, sobre todo, en los oprimidos de los estratos medios, cuyo anhelo es llegar a ser iguales al "hombre ilustre" de la denominada clase "superior". (FREIRE, 1987, p. 58)

Esta enajenación, o alienación en términos de Fanon, lleva al oprimido a la fascinación por el opresor. Supone que a través de una adherencia al mundo del colonizador pueda superarse la situación de colonización, de opresión. 
Confluencias entre el pensamiento de Frantz Fanon y el de Paulo Freire. E surgimiento de la educación popular en el marco de la situación colonial

El trabajo de Freire tiene la riqueza de haber construido estas elaboraciones a través del trabajo directo con campesinos en proceso de alfabetización en los círculos de cultura generados en Brasil, antes del golpe de estado de 1964. El material recogido a lo largo de estas experiencias había sido poco elaborado teóricamente debido a las exigencias prácticas que el desarrollo de los círculos imponía. Ya en el exilio, Freire va a poder trabajar con estos materiales, analizándolos a la luz de diversas perspectivas teóricas. En este caso, creemos que la lectura de la obra de Fanon constituyó un aporte fundamental.

Un matiz debe señalarse en cuanto a la forma como Fanon elabora este tema. Para él, no se trata exactamente que el colonizado quiera ser igual que el colonizador, sino que quiere ocupar su lugar, sustituirlo. No se trata de integrarse en el orden del colonizado, sino de ocupar su lugar en ese orden. De este modo:

La mirada que el colonizado lanza sobre la ciudad del colono es una mirada de lujuria, de deseo. Sueños de posesión. Todos los modos de posesión: sentarse a la mesa del colono, acostarse en la cama del colono, si es posible con su mujer. [...] Es verdad, no hay un colonizado que no sueñe cuando menos una vez al día en instalarse en el lugar del colono. (FANON, 1974, p. 34)

De este modo, lo que está en juego no es el orden colonial, sino el lugar que los diversos sujetos ocupan en el. Podemos apreciar una complementariedad en las formas de construir la situación de alienación en ambos autores.

4) La existencia de un sentimiento de desvalorización por parte de los oprimidos. Se trata de la introyección de la visión desvalorizada acerca de los oprimidos que los opresores lanzan sobre aquellos. En definitiva:

De tanto oír de si mismos que son incapaces, que no saben nada, que no pueden saber, que son enfermos, indolentes, que no producen en virtud de todo esto, terminan por convencerse de su incapacidad. Hablan de si mismo como los que no saben y del profesional como quien sabe y a quien deben escuchar. (FREIRE, 1987, p. 58-59)

La asunción por los oprimidos de su radical incompetencia en relación a lo opresores constituye para Freire una de las bases del sistema de opresión. Este punto se relaciona con el anterior, en la medida que quien ocupa una situación de poder es reconocido como ontológicamente superior. 


\title{
Pablo Martins
}

En el pensamiento de Fanon también tiene un lugar importante la constatación acerca de la imagen de desvalorización de los colonizados que los colonos construyen y difunden acerca de los colonos. En sus palabras:

\begin{abstract}
La sociedad colonizada no solo se define como una sociedad sin valores. No le basta al colono afirmar que los valores han abandonado o, mejor aún, no han habitado jamás el mundo colonizado. [...] Las costumbres del colonizado, sus tradiciones, sus mitos, sobre todo sus mitos, son la señal misma de esa indigencia, de esa depravación constitucional. (FANON, 1974, p. 36)
\end{abstract}

Esta construcción acerca del colono tiene la función de generar una visión del colonizado funcional al mantenimiento de la situación colonial. Se genera y difunde una ideología para lograr convencer al colono de su natural relación de dependencia en relación al colono.

De todos modos en el pensamiento de Fanon esta difusión de una ideología nunca llega a imponerse totalmente en la mente del colonizado. En este sentido,

Pero el colonizado, que comprende el proyecto del colono, el proceso exacto que pretende hacerle seguir, sabe inmediatamente en que piensa. [...] El colonizado sabe todo eso y ríe cada vez que se descubre como animal en las palabras del otro. Porque sabe que no es animal. $Y$ precisamente, al mismo tiempo que descubre su humanidad, comienza a bruñir sus armas para hacerla triunfar. (FANON, 1974, p. 37)

Fanon aprecia la tensión existente en la mente del oprimido entre la asunción de la versión que el colonizado genera sobre su cultura y la percepción de su situación de deshumanización y la necesidad de trascenderla.

El momento en que el colonizado descubre su humanidad negada comienza el proceso por la recuperación de la misma. Este elemento también es rescatado por Freire, como trabajaremos más adelante.

\section{La reflexión sobre el papel de los intelectuales}

Otro elementos común entre el pensamiento de Fanon y el de Freire se refiere al papel de los intelectuales en un proceso de cambio social.

Ambos autores distinguen diversas etapas por las que transitan aquellos intelectuales que pretenden involucrarse superar la situación colonial o de opresión. 
Confluencias entre el pensamiento de Frantz Fanon y el de Paulo Freire. El surgimiento de la educación popular en el marco de la situación colonial

Fanon plantea tres momentos en la evolución de un intelectual colonizado que tienda a asumir una postura anticolonial. Estas son:

a) período "asimilacionista integral";

b) período en que "se estremece y decide recordar";

c) período de lucha.

En el primer momento, "el intelectual colonizado prueba que ha asimilado la cultura del ocupante. Sus obras corresponden punto por punto con las de sus homólogos metropolitanos" (FANON, 1974, p. 201-202). Es el momento en el que se mantiene intacta la fascinación por la cultura del colono, comprendida como superior a la propia.

En el segundo momento, de crisis, el colonizado va retomando su contacto con su pueblo. En este radica la esencia de la nación, no doblegada por la situación colonial. Todavía la relación con el pueblo no es de reinserción plena, el intelectual aún "mantiene relaciones de exterioridad con el pueblo, se contenta con recordar. [...] Período de angustia, de malestar, experiencia de muerte, experiencia de la náusea. Se vomita, pero ya, por debajo, se prepara la risa". (FANON, 1978, p. 203)

En un tercer momento el colonizado asume una postura consciente hacia la superación de la situación colonial. El intelectual, "tras haber intentado perderse en el pueblo, perderse con el pueblo, va por el contrario a sacudir al pueblo. En vez de favorecer el letargo se transforma en el que despierta al pueblo. Literatura de combate, literatura revolucionaria, literatura nacional" (FANON, 1978, p. 203). El intelectual asume una postura consciente por la superación de la situación colonial. De todos modos lleva en sí la tensión del conocimiento adquirido del colonizador, lo cual le genera contradicciones.

Para Freire, el intelectual que asume la causa de los oprimidos debe realizar una travesía. Apartarse de su papel como parte de una situación social injusta y asumir una postura a favor de la humanización de todos. En este sentido:

El hombre radical, comprometido con la liberación de los hombres, no se deja prender en "círculos de seguridad" en los cuales aprisiona también la realidad. Por el contrario, es tanto más radical cuanto más se inserta en esta realidad para, a fin de conocerla mejor, transformarla mejor.

No teme enfrentar, no teme escuchar, no teme el descubrimiento del mundo. No teme el encuentro con el pueblo. (FREIRE, 1987, p. 26)

En ambas posturas queda claro que la toma de posición por la superación de las relaciones de opresión supone renunciar a situaciones de privilegio, asumir la vinculación con el pueblo y trabajar por su liberación. 


\title{
Pablo Martins
}

\section{El papel del lumpen-proletariado en la transformación social}

Otro elemento que caracteriza y relaciona las obras de Fanon y de Freire es su planteo acerca del papel activo que han de desarrollar los sectores más oprimidos en la superación de la opresión.

En Fanon, la reivindicación del carácter revolucionario del lumpen-proletariado ocupa un lugar central. En este sentido se separa del pensamiento habitual en el marxismo tradicional, que enfatiza el inmovilismo de este sector. Este ha sido un aspecto que ha sido adecuadamente valorado por diversos estudiosos de la obra de Fanon. Ello puede apreciarse en el siguiente fragmento de Peter Worsley:

\begin{abstract}
Los factores claves del cambio revolucionario son, para Fanon, el campesinado y el lumpen-proletariado, aunque - para luchar con éxito - deben unirse a los "intelectuales urbanos", algunos de los cuales "van hacia el pueblo" en el campo y comienzan a vivir y a trabajar con él. [...] El subrayado de Fanon del potencial revolucionario el lumpen-proletariado, sin embargo, es provocativo y mucho menos familiar; que yo sepa, es el único pensador contemporáneo importante que lo haya propuesto seriamente. (WORSLEY, 1970, p. 43-44)
\end{abstract}

Esta afirmación del papel revolucionario de los sectores más oprimidos de la sociedad colonial ubica a Fanon en un espacio particular entre los pensadores de la situación colonial. También es un elemento fundamental en la relación entre su pensamiento y el de Freire.

En Freire existe también la afirmación de la participación de los sectores más oprimidos de la sociedad en su transformación. La afirmación del potencial revolucionario de este sector no es un acto gratuito ni la expresión de una postura ingenuamente idealista. Ambos autores coinciden en el hecho que la asunción de ese rol supone la toma de conciencia de la situación de opresión. Plantea Freire:

\begin{abstract}
Hasta el momento en que los oprimidos no toman conciencia de las razones de su estado de opresión, "aceptan" fatalistamente su explotación. [...] Este descubrimiento, sin embargo, no puede ser hecho a un nivel meramente intelectual, sino que debe estar asociado a un intento serio de reflexión, a fin que sea praxis. (FREIRE, 1987, p. 60-61)
\end{abstract}

\section{Breves conclusiones}

A través del desarrollo el presente trabajo hemos pretendido realizar un abordaje inicial del surgimiento de la corriente de educación liberadora o 
Confluencias entre el pensamiento de Frantz Fanon y el de Paulo Freire. E surgimiento de la educación popular en el marco de la situación colonial

popular, específicamente en el marco de las elaboraciones acerca de la sociedad colonial.

Particularmente, hemos pretendido abordar puntos de convergencia entre la obra de Frantz Fanon y las elaboraciones pedagógicas de Paulo Freire.

Al finalizar el trabajo queremos plantear que, si bien no es posible hablar de una continuidad absoluta y lineal entre el pensamiento de ambos autores, es posible detectar la existencia de numerosos puntos en común y formas similares de acercarse a diversos temas. En este sentido creemos que queda registrada la influencia fanoniana en la obra de Freire.

Más allá inclusive que la existencia de abordajes particulares congruentes, creemos que es posible hacer referencia a la existencia de un enfoque común en lo que tiene que ver con la conceptualización de la sociedad colonizada - oprimida, las formas a través de las cuales los oprimidos se constituyen en sujetos de esa sociedad y las posibilidades de transformación de las relaciones de deshumanización en relaciones de humanidad plena.

Apreciamos que estos elementos de convergencia pueden resultar interesantes para pensar los desafíos que actualmente se presentan a la educación en términos generales y a la educación popular en particular. A título de mayores desarrollos que deberán realizarse en el futuro, nos parece relevante señalar tres ejes posibles de intervención en los debates y prácticas educativas desde las líneas trazadas previamente en este artículo.

Por una parte, surge como una tarea impostergable reivindicar el carácter humanizador de la educación. Esto implica rechazar toda perspectiva pedagógica que pueda ser funcional al establecimiento de relaciones de subordinación entre diversos sectores o clases sociales. Lejos de ello, rescatar el legado de Fanon y de Freire supone trabajar por una educación donde todos los educandos sean reconocidos en su dignidad humana y donde la construcción de los contenidos temáticos recupere a los sujetos populares como actores fundamentales.

En segundo término, deberíamos reflexionar acerca de las implicancias políticas asociadas al trabajo de los intelectuales. Siguiendo a Fanon y a Freire es inevitable sostener que la producción de nuevos conocimientos y la reflexión sobre lo social, lo cultural y lo humano posee siempre un carácter político. Trabajar desde este principio en la educación, en todos los ámbitos que esta abarca, constituye un elemento fundamental para trabajar contra las desigualdades instaladas en nuestras sociedades.

Finalmente, entendemos que no es posible pensar una educación transformadora y popular sin reconocer el lugar central que ocupan los sectores populares en las transformaciones sociales necesarias para superar las desi- 
gualdades sociales instaladas en nuestras sociedades. Reconocer al otro como un sujeto de derechos y de posibilidades, resulta un elemento fundamental para la construcción de una educación popular y es, probablemente, el mayor aprendizaje que podamos extraer del cruce que hemos intentado realizar de las obras de Franz Fanon y Paulo Freire.

\section{Referências}

ANDREOLA, B. Interdisciplinaridade na obra de Freire: uma pedagogia da simbiogenese e da solidariedade. In: STRECK, D. (Org.). Paulo Freire. Ética, utopia e educação, Petrópolis: Vozes, 1999.

AROCENA, R. La cuestión del desarrollo vista desde América Latina. Montevideo: EUDECI, 1995.

CARDOZO, F. H.; FALLETTO, E. Desarrollo y dependencia en América Latina. Ensayo de interpretación sociológica. 1969.

COLLOTI, E. "Fanonismo" y “Cuestión colonial”, en AA.VV. (1970), Frantz Fanon y la revolución colonial, Buenos Aires, Ed. del Siglo. 1970.

CÓRDOBA, R. Prólogo, en AA.VV. (1970), Frantz Fanon y la revolución coIonial, Buenos Aires, Ed. del Siglo. 1970.

FANON, F. Los condenados de la Tierra, Buenos Aires, Fondo de Cultura Económica. (Primera edición en francés: FANON, Frantz (1961), Les damés de la terre, Paris, Maspero.). 1974.

FREIRE, P. (1986, 36a edición), La educación como práctica de la libertad, Madrid, Sigo XXI - Tierra Nueva (primera edición en español de 1969).

edición en español de 1970).

. Pedagogía de la Esperanza. México: Siglo XXI, 1993.

GADOTTI, M.; TORRES, C. A. Paulo Freire: una biobibliografía. Buenos Aires: Siglo XXI, 2001.

GEISMAR, P. Frantz Fanon: evolución de un revolucionario, en AA.VV. (1970), Frantz Fanon y la revolución colonial, Buenos Aires, Ed. del Siglo. 1970.

GHIGGI, G. (s/f): A autoridade a serviço da liberdade: diálogos com Paulo Freire e professores em formação, UFPel.

GIROUX, H. Placeres inquietantes. Barcelona: Paidós, 1996.

MEDINA ECHAVARRÍA, J. Filosofía, educación y desarrollo. México: Siglo XXI, 1967.

PUIGGRÓS, A. Sujetos, disciplinas y currículum en los orígenes del sistema educativo argentino. Buenos Aires: Galerna, 1990. 
Confluencias entre el pensamiento de Frantz Fanon y el de Paulo Freire. EI surgimiento de la educación popular en el marco de la situación colonial

PUIGGRÓS, A. Imaginación y crisis en la educación latinoamericana. Buenos Aires: Aique, 1994.

SCOCUGLIA, A. A construção da história das idéias de Paulo Freire. In: STRECK, D. (Org.). Paulo Freire. Ética, utopia e educação, Petrópolis: Vozes, 1999.

WORSLEY, P. La teoría revolucionaria de Frantz Fanon, en AA.VV. (1970), Frantz Fanon y la revolución colonial. Buenos Aires: Ed. del Siglo, 1970.

\section{Correspondência}

Pablo Martins - Maturana 953 esq. Bulevar Artigas (Plaza Cuba), CP 11800, Montevideo, Uruguay.

E-mail:pablomartinis@gmail.com

Recebido em 07 de julho de 2011

Aprovado em 24 de janeiro de 2012 